\title{
Increased stomach cancer risk following radiotherapy for testicular cancer
}

M Hauptmann *,1, S D Fossa ${ }^{2}$, M Stovall ${ }^{3}$, F E van Leeuwen ${ }^{1}$, T B Johannesen ${ }^{4}$, P Rajaraman ${ }^{5}$, E S Gilbert ${ }^{5}$, S A Smith ${ }^{3}$, R E Weathers ${ }^{3}$, B M P Aleman ${ }^{1,6}$, M Andersson $^{7}$, R E Curtis ${ }^{5}$, G M Dores ${ }^{5,8}$, J F Fraumeni ${ }^{5}$, P Hall ${ }^{9,10}$, E J Holowaty ${ }^{11}$, H Joensuu ${ }^{12}$, M Kaijser ${ }^{9}$, R A Kleinerman ${ }^{5}$, F Langmark ${ }^{4}$, C F Lynch ${ }^{13}$, E Pukkala ${ }^{14,15}$, H H Storm ${ }^{16}$, L Vaalavirta ${ }^{12}$, A W van den Belt-Dusebout ${ }^{1}, \mathrm{~L} \mathrm{~B}$ Travis $^{17}$ and L M Morton ${ }^{5}$

${ }^{1}$ Department of Epidemiology and Biostatistics, The Netherlands Cancer Institute, Plesmanlaan 121, 1066 CX Amsterdam, The Netherlands; ${ }^{2}$ Department of Oncology, Oslo University Hospital and University of Oslo, Oslo, Norway; ${ }^{3}$ Department of Radiation Physics, The University of Texas MD Anderson Cancer Center, Houston, TX, USA; ${ }^{4}$ Cancer Registry of Norway, Oslo, Norway; ${ }^{5}$ ivision of Cancer Epidemiology and Genetics, National Cancer Institute, NIH, DHHS, Bethesda, MD, USA; ${ }^{6}$ Department of Radiation Oncology, The Netherlands Cancer Institute, Amsterdam, The Netherlands; ${ }^{7}$ Department of Oncology, Copenhagen University Hospital, Copenhagen, Denmark; ${ }^{8}$ Department of Veterans Affairs Medical Center, Oklahoma City, OK, USA; ${ }^{9}$ Department of Medical Epidemiology and Biostatistics, Karolinska Institutet, Stockholm, Sweden; ${ }^{10}$ Clinical Epidemiology Unit, Department of Medicine, Karolinska Institutet, Stockholm, Sweden; ${ }^{11}$ Dalla Lana School of Public Health, University of Toronto, Toronto, Ontario, Canada; ${ }^{12}$ Department of Oncology, Helsinki University Central Hospital, Helsinki, Finland; ${ }^{13}$ Department of Epidemiology, University of lowa, lowa City, IA, USA; ${ }^{14}$ Finnish Cancer Registry, Institute for Statistical and Epidemiological Cancer Research, Helsinki, Finland; ${ }^{15}$ School of Health Sciences, University of Tampere, Tampere, Finland; ${ }^{16}$ Cancer Prevention and Documentation, Danish Cancer Society, Copenhagen, Denmark and ${ }^{17}$ Department of Radiation Oncology, University of Rochester Medical Center, Rochester, NY, USA

Background: Abdominal radiotherapy for testicular cancer (TC) increases risk for second stomach cancer, although data on the radiation dose-response relationship are sparse.

Methods: In a cohort of 22269 5-year TC survivors diagnosed during 1959-1987, doses to stomach subsites were estimated for 92 patients who developed stomach cancer and 180 matched controls. Chemotherapy details were recorded. Odds ratios (ORs) were estimated using logistic regression.

Results: Cumulative incidence of second primary stomach cancer was $1.45 \%$ at 30 years after TC diagnosis. The TC survivors who received radiotherapy (87 (95\%) cases, 151 (84\%) controls) had a 5.9-fold (95\% confidence interval (Cl) 1.7-20.7) increased risk of stomach cancer. Risk increased with increasing stomach dose ( $P$-trend<0.001), with an OR of 20.5 (3.7-114.3) for $\geqslant 50.0$ Gy compared with $<10$ Gy. Radiation-related risks remained elevated $\geqslant 20$ years after exposure $(P<0.001)$. Risk after any chemotherapy was not elevated (OR $=1.1 ; 95 \% \mathrm{Cl} 0.5-2.5 ; 14$ cases and 23 controls).

Conclusions: Radiotherapy for TC involving parts of the stomach increased gastric cancer risk for several decades, with the highest risks after stomach doses of $\geqslant 30 \mathrm{~Gy}$. Clinicians should be aware of these excesses when previously irradiated TC survivors present with gastrointestinal symptoms and when any radiotherapy is considered in newly diagnosed TC patients.

The incidence of testicular cancer (TC), the most common malignancy affecting males aged 15-34 years in the United States and Europe (McGlynn et al, 2003; Garner et al, 2005), has continuously increased over the past 30 years (Chia et al, 2010). As a result of the introduction of radiotherapy in the 1950s and cisplatin-containing combination chemotherapy in 1978

*Correspondence: Dr M Hauptmann; E-mail: m.hauptmann@nki.nl

Received 1 June 2014; revised 2 October 2014; accepted 4 October 2014; published online 4 November 2014

(C) 2015 Cancer Research UK. All rights reserved 0007 - 0920/15 
(Einhorn and Donohue, 1977), TC is currently among the most curable solid tumours, with 10-year relative survival reaching $95 \%$ (Biggs and Schwartz, 2007; Verdecchia et al, 2007).

Previous studies of TC survivors have demonstrated increased risks for treatment-related second solid malignancies, beginning 10-15 years after initial diagnosis, with stomach cancer being of particular concern among TC survivors, given reported standardised incidence ratios ranging from 2.0 to 9.2 (Van Leeuwen et al, 1993; Travis et al, 1997; Kollmannsberger et al, 1999; Travis et al, 2005; Robinson et al, 2007; Van den Belt-Dusebout et al, 2007; Horwich et al, 2014). Although excess cases have been most often attributed to radiotherapy, the effects of radiation dose to the stomach have not been assessed in large studies. Furthermore, although some investigations among Hodgkin's lymphoma survivors reported especially high risks after combined radiotherapy and chemotherapy (Mauch et al, 1996; Birdwell et al, 1997; Swerdlow et al, 2000; Van Leeuwen et al, 2000; Foss Abrahamsen et al, 2002; Morton et al, 2013), the effects of specific chemotherapy agents and doses on stomach cancer risk after TC have not been examined. Therefore, in an international cohort of 222695 -year survivors of TC, we evaluated treatment-related stomach cancer risk based on estimated radiation dose to the stomach and dose of chemotherapeutic agents for 92 stomach cancer patients and 180 individually matched controls.

\section{MATERIALS AND METHODS}

Patient selection. During 2003-2009, we studied 22269 5-year survivors of histologically confirmed TC as their first primary cancer (except non-melanoma skin cancer), including 19562 patients identified from population-based cancer registries in Denmark (1943-1999), Finland (1953-2002), Iowa, USA (1973-2001), Ontario, Canada (1964-2003), Sweden (1958-2002) and Norway (1953-2000). We observed 111 cases of second primary stomach cancer diagnosed during 1975-2004. Medical records were obtained for 70 cases $(63 \%)$. Most TC patients without medical records $(N=30,73.2 \%)$ were diagnosed before 1970 (Supplementary Material). We randomly selected two controls per case $(N=140)$ who survived TC without a second cancer at least as long as the corresponding case and individually matched the case by registry, birth date and date of TC diagnosis (both within 2 years that was relaxed, if necessary, to 5 years). Medical records were located for 128 controls $(91 \%)$. We then sought additional controls to reach a target of 2 controls per case, resulting in a total of 130 controls.

We identified 18 cases and 36 controls from Norway and all had received primary treatment in the Radium Hospital. In 2008-2009, we attempted to expand the original Norwegian study to include an additional 18 cases and 36 controls treated at other hospitals in Norway. However, upon review of the data, we excluded nonRadium Hospital patients because of insufficient information for dose reconstruction in the medical records (33\% vs $4 \%$ among all other cases and controls) and a suggestive bias in ascertainment of exposure information (Supplementary Material).

We also included 22 cases and 50 controls, matched on age and year of TC diagnosis, from a Dutch hospital-based case-control study of second primary stomach cancer among 2707 5-year survivors of TC treated in 1965-1995 and followed through 2002. These patients were included in a previous report (Van den Belt-Dusebout et al, 2009). The final analytic population therefore comprised 272 TC patients (diagnosed 1959-1987), including 92 stomach cancer cases (diagnosed 1975-2004) and 180 matched controls.

The study was approved by either the Institutional Review Boards in each study centre or by the Data Inspectorate concerning national data, and exempted from review by the Netherlands Cancer Institute and the National Cancer Institute because only existing de-identified data were used.
Data collection. Details on patient demographics, including height and weight, and TC diagnosis and treatment were abstracted from available records in a standardised manner. Medical and pathology records were reviewed for stomach cancer cases to confirm diagnosis and determine tumour location in the stomach. Chemotherapy data were abstracted for: dates of administration, regimens, number of cycles, drugs, doses (alkylating agents and topoisomerase inhibitors), route of administration and indication (initial or subsequent therapy). Cumulative doses $\left(\mathrm{mg} \mathrm{m}^{-2}\right)$ were calculated for individual agents.

Abstracted radiotherapy details included dates of administration, indication (initial or subsequent therapy), beam energy, delivered dose, field location and configuration. Patients were generally treated with dog-leg (including para-aortic and ipsilateral iliac nodes) or para-aortic fields. Daily target doses were 1.8$2.0 \mathrm{~Gy}$, resulting in cumulative doses typically ranging from 25 to 50 Gy. Radiation doses to the stomach were similarly estimated for all cases and controls, using a custom-designed dose programme, based on measurements in water and anthropomorphic phantoms constructed of tissue-equivalent material (Stovall et al, 2006). Using individual patients treatment parameters, dose was calculated to 464 points in the stomach based on a typical stomach configuration (Supplementary Figure 1) (Leibel and Phillips, 2004), summing all radiotherapy series.

Stomach size, shape and location exhibit intra- and interindividual variation depending on stomach contents, respiration, abdominal muscle tone and body build (Dowd and Wilson, 1995). Stomach position was unknown for individual patients in the study and likely varied over the course of radiotherapy. Therefore, in addition to the typical J-shaped stomach configuration, we estimated radiation doses to two alternative stomach configurations for sensitivity analyses (Supplementary Figure 1).

Radiation received within 5 years of stomach cancer diagnosis (or equivalent date for controls) were not included in the stomach doses because these were unlikely to have contributed to the stomach cancer. Analyses of radiotherapy risks used the mean dose to the stomach tumour location (same location for matched controls), specified as cardia, fundus, body, lesser curvature, greater curvature, antrum or pylorus. For $2(2 \%)$ cases with unspecified tumour location, analyses used mean dose to the entire stomach.

Statistical analysis. Cumulative incidence of second primary invasive stomach cancer in the population-based cohort was calculated with death and other second cancers as competing risks (Gooley et al, 1999). The relative risk of stomach cancer was estimated using odds ratios (ORs) and 95\% confidence intervals (CIs) derived from conditional logistic regression (Breslow and Day, 1980), comparing exposure histories among cases to those of matched controls. Radiation dose-response was evaluated by $10 \mathrm{~Gy}$ categories. In addition, the excess odds ratio (EOR) per Gy was estimated by the linear dose-response model OR $=\operatorname{EXP}\left(\sum_{j} \alpha_{j} X_{j}\right)[1+$ $\beta D$ ], where $D$ is radiation dose in $\mathrm{Gy}, \beta$ is the EOR/Gy and the $X_{\mathrm{j}}$ are covariates (e.g., chemotherapy) with corresponding log ORs $\alpha_{j}$. Departure from linearity was evaluated by a likelihood ratio test of the null hypothesis $\gamma=0$ in a model including dose as an exponential factor $\mathrm{OR}=\operatorname{EXP}\left(\Sigma_{j} \alpha_{j} X_{\mathrm{j}}\right)\left[1+\beta D^{*} \operatorname{EXP}(\gamma D)\right]$, where $\gamma$ indicates downward $(\gamma<0)$ or upward curvature $(\gamma>0)$ in the EOR/ Gy. In order to accommodate a local minimum or maximum in the dose-response curve, we also fitted a cubic truncated power spline with knots at tertiles of dose among cases with nonmissing dose (22.1 and $36.1 \mathrm{~Gy}$ ). Missing radiotherapy dose was handled by including an indicator variable in all analyses.

Odds ratios were assessed by having ever $v s$ never received any chemotherapeutic drug reported in the study population adjusting for radiation dose in categories as specified in Table 2. Odds ratios were also calculated by categories of cisplatin dose, the most commonly administered drug, as well as the number of 
chemotherapy cycles with alkylating agents, with categories based on approximately equal numbers of cases per category (Table 2).

Heterogeneity in risks among patient subgroups under a multiplicative model was evaluated by comparing the goodness of fit of models including separate ORs and EORs for each subgroup and a single estimate, respectively. We performed sensitivity analyses by registry (leaving out each registry one at a time), stomach shape (Supplementary Figure 1) and tightness of matching of controls, and by excluding cases with a prior partial gastrectomy $(N=4)$ or controls who did not match the case within 5 years with regard to year of birth $(N=2)$, year of TC diagnosis $(N=1)$ or follow-up window $(N=3)$. SAS (SAS Institute Inc., Cary, NC, USA; version 9.2) and EPICURE (Preston et al, 1993) software were used.

\section{RESULTS}

Median age at TC diagnosis was 38 years (range, 18-71), 67\% of all patients had been treated for a seminoma and almost all had stage I or II disease (92\%) at TC diagnosis (Table 1). Treatment for TC included surgery and radiotherapy only $(80 \%$ cases and $78 \%$ controls); surgery, radiotherapy and chemotherapy (14\% cases and

Table 1. Characteristics of testicular cancer survivors who developed stomach cancer and matched controls ${ }^{a}$

\begin{tabular}{|c|c|c|}
\hline & $\begin{array}{c}\text { Cases } \\
(\mathbf{N}=92)\end{array}$ & $\begin{array}{c}\text { Controls } \\
(N=180)\end{array}$ \\
\hline & $N(\%)$ & $N(\%)$ \\
\hline \multicolumn{3}{|l|}{ Registry $^{b}$} \\
\hline The Netherlands ${ }^{c}$ & $22(23.9)$ & $50(27.8)$ \\
\hline Sweden & $20(21.7)$ & $40(22.2)$ \\
\hline Denmark & $20(21.7)$ & $30(16.7)$ \\
\hline Norway & $18(19.6)$ & $36(20.0)$ \\
\hline Finland & $7(7.6)$ & $14(7.8)$ \\
\hline Ontario & $5(5.4)$ & $10(5.6)$ \\
\hline \multicolumn{3}{|l|}{ Year of testicular cancer diagnosis } \\
\hline $1959-1969$ & $28(30.4)$ & $51(28.3)$ \\
\hline 1970-1979 & $44(47.8)$ & $87(48.3)$ \\
\hline 1980-1987 & $20(21.7)$ & $42(23.3)$ \\
\hline \multicolumn{3}{|c|}{ Age at testicular cancer diagnosis (years) } \\
\hline $18-29$ & $17(18.5)$ & $36(20.0)$ \\
\hline 30-39 & $35(38.0)$ & $70(38.9)$ \\
\hline 40-49 & $23(25.0)$ & $42(23.3)$ \\
\hline $50-59$ & $12(13.0)$ & $23(12.8)$ \\
\hline $60-71$ & $5(5.4)$ & $9(5.0)$ \\
\hline \multicolumn{3}{|l|}{ Testicular cancer histology } \\
\hline Seminoma & $60(65.2)$ & $121(67.2)$ \\
\hline Non-seminoma & $32(34.8)$ & $58(32.2)$ \\
\hline Other $^{d}$ & $0(0)$ & $1(0.6)$ \\
\hline \multicolumn{3}{|l|}{ Testicular cancer stage } \\
\hline $\mid / \|^{e}$ & $88(95.7)$ & $172(95.6)$ \\
\hline III/IV & $4(4.3)$ & $6(3.3)$ \\
\hline Unknown & $0(0)$ & $2(1.1)$ \\
\hline \multicolumn{3}{|l|}{ Testicular cancer laterality } \\
\hline Left & $37(40.2)$ & $78(43.3)$ \\
\hline Right & $54(58.7)$ & $100(55.6)$ \\
\hline Synchronous & $1(1.1)$ & $1(0.6)$ \\
\hline Unknown & $0(0)$ & $1(0.6)$ \\
\hline \multicolumn{3}{|c|}{ Testicular cancer treatment following orchiectomy } \\
\hline Radiotherapy only & $74(80.4)$ & $141(78.3)$ \\
\hline Radiotherapy and chemotherapy & $13(14.1)$ & $10(5.6)$ \\
\hline Chemotherapy only & $1(1.1)$ & $13(7.2)$ \\
\hline No chemotherapy, no radiotherapy & $3(3.3)$ & $16(8.9)$ \\
\hline Unknown & $1(1.1)$ & $0(0)$ \\
\hline
\end{tabular}

\section{Table 1. (Continued)}

.
radiotherapy)
Radiation treatment fields (for patients who received

\begin{tabular}{|l|c|c|}
\hline Dog-leg/inverted Y/spade only & $28(32.2)$ & $70(46.4)$ \\
Dog-leg/inverted Y/spade plus pelvis only & $1(1.1)$ & $3(2.0)$ \\
$\begin{array}{l}\text { Dog-leg/inverted Y/spade plus } \\
\text { supradiaphragmatic fields (mediastinum, neck/ }\end{array}$ & $10(11.5)$ & $7(4.6)$ \\
$\begin{array}{l}\text { supraclavicular, other chest) only } \\
\text { Para-aortic plus pelvis only }\end{array}$ & \\
Others & $22(25.3)$ & $30(19.9)$ \\
\hline & $26(29.9)$ & $41(27.2)$
\end{tabular}

Interval from testicular cancer to stomach cancer (years)

\begin{tabular}{|l|c|}
\hline $7-9$ & $9(9.8)$ \\
$10-14$ & $26(28.3)$ \\
$15-19$ & $23(25.0)$ \\
$20-24$ & $23(25.0)$ \\
$25-39$ & $11(12.0)$
\end{tabular}

Year of stomach cancer diagnosis

\begin{tabular}{|l|l|}
\hline $1975-1984$ & $20(21.7)$ \\
$1985-1994$ & $39(42.4)$ \\
$1995-2004$ & $33(35.9)$
\end{tabular}

Age at stomach cancer diagnosis (years)

\begin{tabular}{|l|l|}
\hline $31-49$ & $24(26.1)$ \\
$50-59$ & $31(33.7)$ \\
$60-80$ & $37(40.2)$ \\
\hline
\end{tabular}

Stomach cancer histology

\begin{tabular}{|l|l|}
\hline Adenocarcinoma & $82(89.1)$ \\
\hline
\end{tabular}

\begin{tabular}{l|l} 
Other/unknown $^{f}$ & $10(10.9)$
\end{tabular}

\section{Stomach cancer site ${ }^{g}$}

\begin{tabular}{|l|l|}
\hline Proximal & $22(23.9)$ \\
\hline Body
\end{tabular}

Body

Lesser curvature

Greater curvature

Distal

Not otherwise specified

$10(10.9)$

$12(13.0)$

$5(5.4)$

$41(44.6)$

${ }^{a}$ Patients were ineligible as cases or controls after the occurrence of a second non-stomach cancer (except metachronous testicular cancer that occurred in 3 cases and 3 controls and non-melanoma skin cancer), because it was logistically not feasible to collect detailed treatment information on multiple cancers.

${ }^{\mathbf{b}}$ Cases and controls were selected from a cohort of 22269 testicular cancer (TC) survivors including 6858 patients from Denmark, 1346 from Finland, 1300 from lowa, 3440 from Ontario, 4732 from Sweden, 1886 from Norway and 2707 from The Netherlands.

c Patients from a previous report (Van den Belt-Dusebout et al, 2009) were included in the current study.

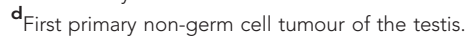

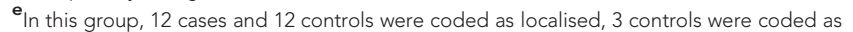
regional and 1 case and 7 controls were coded as localised/regional.

f Includes 5 carcinoma not otherwise specified, 1 neuroendocrine carcinoma, 1 other specified and 3 unknown.

9Proximal includes cardia ( $n=17$ cases), stump cancer (4) and gastro-oesophageal junction (1); body includes body (8), fundus/body (1), body/antrum (1); distal includes antrum (25), pylorus (15) and antrum/pylorus (1).

$6 \%$ controls); surgery only ( $3 \%$ cases and $9 \%$ controls); and surgery and chemotherapy only (1\% cases and $7 \%$ controls).

In the population-based cohort, the cumulative incidence of second primary invasive stomach cancer was $0.30 \%$ (95\% CI 0.20 $0.39 \%)$ at 15 years and $1.45 \%$ (95\% CI $1.15-1.74 \%)$ at 30 years after TC diagnosis. Of all stomach cancers (median age at diagnosis, 58 years; range, $31-80), 37 \%$ occurred $\geqslant 20$ years after TC diagnosis (median, 17; range, 7-39).

Three types of fields delivered the highest radiation doses to the stomach: dog-leg (58\% of patients), para-aortic (32\%) and other abdominal (9\%) (Figure 1). Mean radiation doses from these fields were highest to the antrum and pylorus (37, 32 and $24 \mathrm{~Gy}$, respectively) and the lesser curvature (34, 28 and $17 \mathrm{~Gy}$, respectively); mean doses to other specific parts of the stomach were $<15 \mathrm{~Gy}$. For all other radiation fields (including 


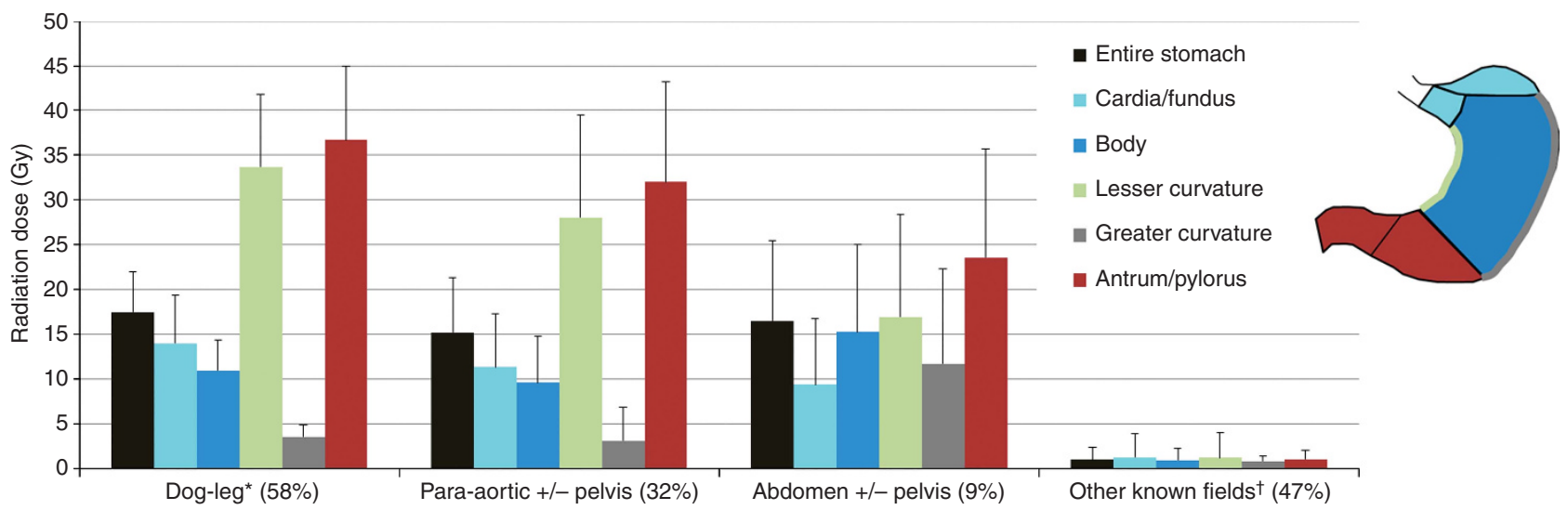

Figure 1. Mean radiation dose of cases and controls to the stomach, by stomach region, for specific testicular cancer radiotherapy fields. Note that percentages add to $>100$ as most patients were treated using more than one field type (parallel and opposing fields are combined for this purpose). *Includes inverted $Y$ and spade. ${ }^{\dagger}$ Other known fields include those to the mediastinum, neck or supraclavicular area, testes, spine, chest other than para-aortic and head.

Table 2. Treatment-related risks for stomach cancer among patients with testicular cancer and matched controls

\begin{tabular}{|c|c|c|c|c|}
\hline & Number of cases & Number of controls & Odds ratio & 95\% Confidence intervals \\
\hline \multicolumn{5}{|l|}{ Any radiotherapy ${ }^{a}$} \\
\hline No & 4 & 29 & 1 & Ref \\
\hline & 87 & 151 & 5.9 & $1.7-20.7$ \\
\hline Unknown & 1 & 0 & $\operatorname{lnf}$ & $0.9-\operatorname{Inf}$ \\
\hline \multicolumn{5}{|l|}{ Radiation dose $(G y)^{a}$} \\
\hline $0-9.9$ & 15 & 49 & 1 & Ref \\
\hline $10.0-19.9$ & 7 & 16 & 2.0 & $0.5-8.7$ \\
\hline $20.0-29.9$ & 17 & 43 & 2.5 & $0.8-7.9$ \\
\hline $30.0-39.9$ & 28 & 39 & 7.2 & $2.1-24.9$ \\
\hline $40.0-49.9$ & 11 & 21 & 6.7 & $1.7-27.1$ \\
\hline$\geqslant 50.0^{\mathrm{b}}$ & 8 & 6 & 20.5 & $3.7-114.3$ \\
\hline Unknown ${ }^{c}$ & 6 & 6 & 4.5 & $1.0-21.5$ \\
\hline$P$-trend ${ }^{d}$ EOR per $\mathrm{Gy}=0.27(95 \% \mathrm{Cl} 0.054-1.44)$ & & & $<0.001$ & \\
\hline \multicolumn{5}{|l|}{ Any chemotherapy ${ }^{e, f}$} \\
\hline No & 77 & 157 & 1 & Ref \\
\hline Yes & 14 & 23 & 1.1 & $0.5-2.5$ \\
\hline Unknown & 1 & 0 & & \\
\hline \multicolumn{5}{|l|}{ Cisplatin $^{e, g, h}$} \\
\hline None & 84 & 170 & 1 & Ref \\
\hline$<500 \mathrm{mg} \mathrm{m}^{-2}$ & 4 & 6 & 1.4 & $0.3-5.6$ \\
\hline$\geqslant 500 \mathrm{mg} \mathrm{m}^{-2}$ & 3 & 4 & 1.3 & $0.2-8.2$ \\
\hline Unknown & 1 & 0 & & \\
\hline$P$-trend ${ }^{i}$ & & & 0.692 & \\
\hline \multicolumn{5}{|c|}{ Number of chemotherapy cycles including alkylating agents ${ }^{e}$} \\
\hline 0 & 80 & 161 & 1 & Ref \\
\hline $1-4$ & 5 & 10 & 0.9 & $0.3-3.0$ \\
\hline$\geqslant 5$ & 5 & 9 & 1.1 & $0.3-3.8$ \\
\hline Unknown & 2 & 1 & & \\
\hline$P$-trend ${ }^{\mathrm{j}}$ & & & 0.245 & \\
\hline \multirow{2}{*}{\multicolumn{5}{|c|}{ Abbreviations: $\mathrm{Cl}=$ confidence interval; $\mathrm{EOR}=$ excess odds ratio; $\mathrm{Gy}=$ gray; Inf = infinity; Ref= reference. }} \\
\hline \multirow{2}{*}{\multicolumn{5}{|c|}{ Bange: 50-59.1 Gy, median: 50.8 Gy. }} \\
\hline & & & & \\
\hline \multicolumn{5}{|c|}{$\begin{array}{l}{ }^{c} \text { For } 11 \text { of } 12 \text { patients with unknown dose, it was established that they had received radiotherapy. All } 12 \text { patients were included in the analysis via a missing dose indicator variable as described } \\
\text { in the Materials and Methods section. }\end{array}$} \\
\hline \multicolumn{5}{|c|}{$\mathrm{d}_{\text {Based on continuous (linear) dose. }}$} \\
\hline \multicolumn{5}{|c|}{${ }_{f}^{\text {Adjusted for radiation dose in seven categories specified in the table. }}$} \\
\hline \multirow{2}{*}{\multicolumn{5}{|c|}{$\begin{array}{l}\text { In all, } 7 \text { cases and } 10 \text { controls received cisplatin, including } 1 \text { case and } 4 \text { controls who also received etoposide and } 1 \text { control who also received doxorubicin; } 1 \text { case received ifosfamide, cisplatin } \\
\text { and etoposide; } 4 \text { cases and } 4 \text { controls received cyclophosphamide, including } 1 \text { control who also received doxorubicin; } 5 \text { controls received exclusively chlorambucil; } 3 \text { cases and } 4 \text { controls } \\
\text { received only antitumour antibiotics other than doxorubicin, epirubicin or mitoxantrone, including } 1 \text { case who also received a vinca alkaloid (specific drug not coded). }\end{array}$}} \\
\hline & & & & \\
\hline \multirow{2}{*}{\multicolumn{5}{|c|}{ 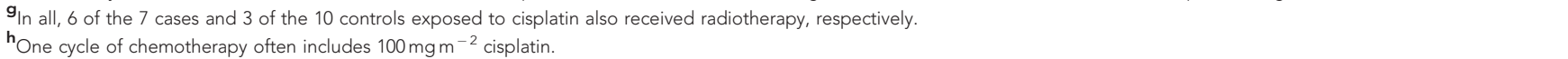 }} \\
\hline & & & & \\
\hline $\begin{array}{l}\text { hone cycle of chemotherapy often includes } 100 \mathrm{mg} \mathrm{m}^{-2} \text { cisplatin. } \\
\text { 'Based on continuous (loglinear) dose. }\end{array}$ & & & & \\
\hline \multicolumn{5}{|c|}{$\mathrm{j}_{\text {Based on continuous (loglinear) number of cycles. }}$} \\
\hline
\end{tabular}




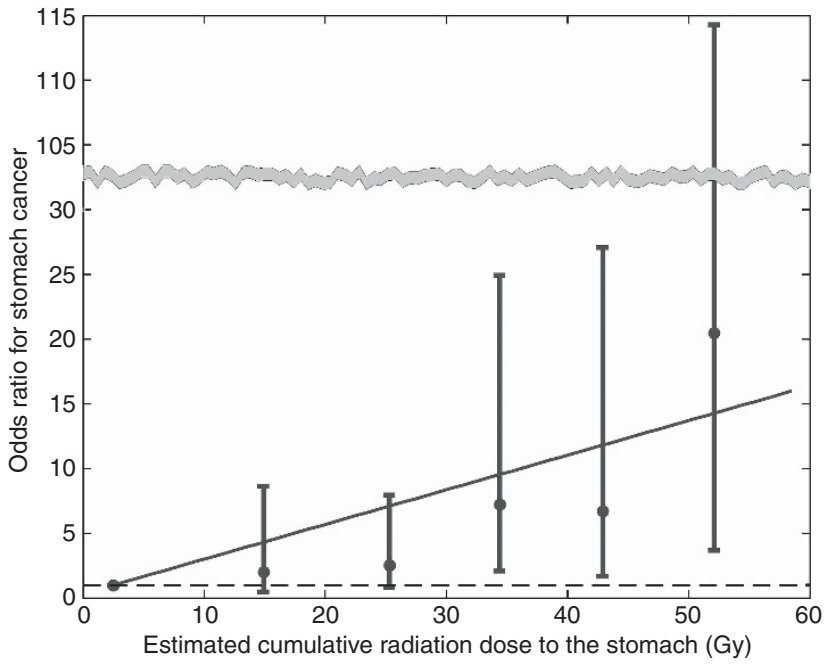

Figure 2. Radiation dose-response relationship for stomach cancer following testicular cancer based on 92 cases and 180 controls. Filled circles and error bars indicate odds ratios and $95 \%$ confidence intervals for categories of dose to the stomach tumour location in cases and a corresponding location in controls (as shown in Table 2) plotted at the mean dose per category. The solid line indicates the linear EOR per Gy $(0.27,95 \% \mathrm{Cl} 0.054-1.44)$ forced to pass through unity (dashed line) at the mean of the reference category ( $2.5 \mathrm{~Gy})$. The ordinate is broken at the horizontal zigzag lines in order to display the upper confidence bound of the highest dose category.

mediastinum, neck or supraclavicular area, testes, spine, chest other than mediastinum and head), the stomach received on average $<3 \mathrm{~Gy}$ to any part. The dose to particular parts of the stomach varied considerably between patients even within the same field type.

Patients who received radiotherapy had a 5.9 -fold (95\% CI $1.7-$ 20.7) increased risk of stomach cancer compared with patients who did not receive radiotherapy (Table 2). Risk increased with increasing dose to the stomach tumour site $(P$-trend $<0.001)$, reaching 20.5 (95\% CI 3.7-114.3) at $\geqslant 50.0 \mathrm{~Gy}$ compared with doses < 10 Gy. The EOR per Gy was 0.27 (95\% CI 0.054-1.44) and consistent with linearity $(P=0.567)$ (Figure 2$)$. A cubic spline did not fit the data better than linearity $(P=0.456)$. Among patients treated with radiotherapy, the estimated proportion of stomach cancers attributable to radiotherapy was 83\% (95\% CI 41-95), and this increased to $87 \%$ (95\% CI 55-96) for patients who received $\geqslant 30 \mathrm{~Gy}$ to the stomach. Radiation-related risks remained increased $\geqslant 20$ years after exposure, based on a significantly elevated EOR per Gy for that period (Table 3).

Chemotherapy did not significantly increase subsequent stomach cancer risk $(\mathrm{OR}=1.1,95 \% \mathrm{CI} 0.5-2.5$, adjusted for radiation dose; Table 2). This was also the case for patients who received alkylating agents ( 11 cases and 19 controls, OR $=1.0,95 \%$ CI $0.4-$ 2.5 ), and those who received cisplatin (7 cases and 10 controls, $\mathrm{OR}=1.4$, 95\% CI 0.4-4.2). No association was observed with cisplatin dose or the number of cycles containing alkylating agents. Based on small numbers of exposed patients, nonsignificant ORs for other individual classes of chemotherapeutic agents ranged from 0.8 for topoisomerase II inhibitors to 1.9 for vinca alkaloids (data not shown). Carboplatin use was not reported for any patient.

Chemotherapy did not influence radiation-related risk estimates that were within $10 \%$ of the crude radiation risks when adjusted for any chemotherapy, any cisplatin, any alkylating agents or categorical cisplatin dose. In addition, there was no evidence indicating that radiation-related risks were modified by chemotherapy or vice versa based on nonsignificant interaction terms between binary indicators of chemotherapy and radiotherapy $(P=0.132)$, or radiation dose above or below $25 \mathrm{~Gy}(P>0.5)$ or continuous radiation dose $(P=0.392)$, added to a multiplicative model for the joint effect. Therefore, the final models on radiation dose were not adjusted for chemotherapy.

We observed larger relative risks for cancers in the distal stomach (infinite EOR per Gy) and body (EOR per Gy=1.48) vs those in the proximal stomach (EOR per $\mathrm{Gy}=0.012$, $P$-homogeneity $=0.012$ ). We observed some evidence for larger relative risks at younger age at TC diagnosis, although age-dependent risks did not differ significantly. Risks did not vary substantially by year of diagnosis and interval from TC to stomach cancer (Table 3).

We performed sensitivity analyses to evaluate the robustness of our findings. Results were similar when each registry was left out one at a time (range EOR per Gy 0.19-0.48) and when we assigned three different stomach shapes based on BMI (Supplementary Material). All major results were only minimally affected when we excluded cases with a prior partial gastrectomy or controls who did not strictly match the case within 5 years for year of birth, year of TC diagnosis or follow-up window.

\section{DISCUSSION}

In an international nested case-control study within a cohort of 22269 5-year survivors of TC, patients who received radiotherapy were at increased risk of developing stomach cancer, particularly those who received $\geqslant 30 \mathrm{~Gy}$ to the stomach. These data are unique for the high proportion of patients who received high-dose radiotherapy to the abdomen in the absence of chemotherapy, thus providing strong evidence for a dose-dependent role of ionising radiation in stomach carcinogenesis. No increased risk was observed after chemotherapy only, although numbers were small.

Previous investigations of stomach cancer risk based on quantitative radiation dose estimates in the absence of chemotherapy are generally consistent with our results, although our study covered a substantially wider range of radiation doses. For example, significantly increased stomach cancer risks were observed in a nested case-control study of stomach cancer after cervical cancer $(\mathrm{EOR}$ per $\mathrm{Gy}=0.11$, mean stomach dose $=2.6 \mathrm{~Gy}$; Kleinerman et al, 2013) and in a study of patients exposed to radiation for peptic ulcer (excess relative risk (ERR) per $\mathrm{Gy}=0.16$, mean stomach dose $=14.8 \mathrm{~Gy}$; Carr et al, 2002) but not for ankylosing spondylitis (Weiss et al, 1994; ERR per $\mathrm{Gy}=-0.004$, mean stomach dose $=3.2 \mathrm{~Gy}$ ).

The EOR per Gy of 0.27 (95\% CI 0.054-1.44) observed in our study was similar in magnitude to the ERR per Gy of 0.21 (90\% CI $0.10-0.34$ ) among male atomic bomb survivors at age 70 years following radiation exposure at age 30 years, both consistent with a linear dose-response (Preston et al, 2007). This is in contrast with lower risks per Gy observed in studies of fractionated, high-dose radiation exposure and second cancer risk (National Council on Radiation Protection and Measurements Scientific Committee 1-17, 2011; Travis et al, 2012; Berrington de Gonzalez et al, 2013). However, comparisons with atomic bomb survivors are uncertain because of the differences in background cancer rates between Japanese and Western populations. Nonetheless, clarifying the magnitude of the risk is essential to refine the development of second solid cancer risk projection models for modern radiotherapy modalities, including intensity-modulated radiotherapy (National Council on Radiation Protection and Measurements Scientific Committee 1-17, 2011; Travis et al, 2012).

Several studies have investigated stomach cancer risk with quantitative radiation dose estimates among patient populations also commonly exposed to chemotherapy. An EOR per Gy of 0.84 
Table 3. Risk of stomach cancer associated with radiation dose by characteristics at testicular cancer diagnosis and other variables $^{\text {a, }}$

\begin{tabular}{|c|c|c|c|c|c|c|c|c|c|}
\hline & \multicolumn{2}{|c|}{ RT dose $<25$ Gy (Ref) } & \multicolumn{2}{|c|}{ RT dose $\geqslant 25 \mathrm{~Gy}$} & \multirow[b]{2}{*}{ OR } & \multirow[b]{2}{*}{$95 \% \mathrm{Cl}$} & \multirow[b]{2}{*}{$P$ hom ${ }^{c}$} & \multirow[b]{2}{*}{ EOR $(P)$} & \multirow[b]{2}{*}{$P$ hom $^{\text {d }}$} \\
\hline & Cases & Controls & Cases & Controls & & & & & \\
\hline All patients & 30 & 83 & 56 & 91 & 3.5 & $1.5-8.6$ & NA & $0.27(<0.001)$ & NA \\
\hline \multicolumn{10}{|c|}{ Age at testicular cancer diagnosis (years) } \\
\hline $18-29$ & 6 & 21 & 11 & 12 & $\operatorname{lnf}$ & 3.5-Inf & & $0.56(0.005)$ & \\
\hline $30-39$ & 12 & 28 & 21 & 41 & 1.8 & $0.4-7.4$ & & $0.47(0.010)$ & \\
\hline $40-71$ & 12 & 34 & 24 & 38 & 3.3 & $0.9-11.4$ & 0.100 & $0.086(0.062)$ & $>0.5$ \\
\hline \multicolumn{10}{|c|}{ Year of testicular cancer diagnosis } \\
\hline 1959-1969 & 11 & 26 & 13 & 21 & 2.3 & $0.6-9.4$ & & $0.17(0.084)$ & \\
\hline 1970-1979 & 10 & 33 & 32 & 53 & 7.1 & $1.4-37.6$ & & $0.50(<0.001)$ & \\
\hline 1980-1987 & 9 & 24 & 11 & 17 & 2.8 & $0.5-15.0$ & $>0.5$ & $0.10(0.234)$ & $>0.5$ \\
\hline \multicolumn{10}{|c|}{ Testicular cancer histology } \\
\hline Non-seminoma & 11 & 33 & 19 & 23 & 6.2 & $1.6-23.6$ & & $1.15(<0.001)$ & \\
\hline Seminoma & 19 & 49 & 37 & 68 & 2.8 & $1.1-7.6$ & 0.268 & $0.16(0.013)$ & 0.210 \\
\hline \multicolumn{10}{|c|}{ Age at stomach cancer diagnosis (years) } \\
\hline $31-49$ & 9 & 29 & 15 & 18 & $\operatorname{lnf}$ & 4.4-Inf & & $0.22(0.014)$ & \\
\hline $50-59$ & 10 & 21 & 19 & 34 & 2.4 & $0.5-12.9$ & & $\operatorname{lnf}(0.033)$ & \\
\hline $60-80$ & 11 & 33 & 22 & 39 & 2.4 & $0.7-7.7$ & 0.076 & $0.24(0.013)$ & $>0.5$ \\
\hline \multicolumn{10}{|c|}{ Year of stomach cancer diagnosis } \\
\hline 1975-1984 & 7 & 21 & 11 & 13 & 8.3 & $1.0-69.9$ & & $0.072(0.081)$ & \\
\hline 1985-1994 & 8 & 25 & 25 & 44 & 5.2 & $0.9-29.6$ & & $\operatorname{lnf}(0.001)$ & \\
\hline 1995-2004 & 15 & 37 & 20 & 34 & 2.0 & $0.6-6.7$ & 0.417 & $0.54(0.007)$ & 0.136 \\
\hline \multicolumn{10}{|c|}{ Stomach cancer site } \\
\hline Proximal & 7 & 20 & 14 & 20 & 2.2 & $0.6-7.9$ & & $0.012(>0.5)$ & \\
\hline Body $^{e}$ & 19 & 32 & 7 & 15 & 0.5 & $0.03-8.0$ & & $1.48(0.003)$ & \\
\hline Distal & 3 & 28 & 35 & 56 & $\operatorname{lnf}$ & $7.1-\operatorname{lnf}$ & 0.012 & $\operatorname{lnf}(<0.001)$ & 0.014 \\
\hline \multicolumn{10}{|c|}{ Interval from testicular cancer to stomach cancer (years) } \\
\hline $7-14$ & 12 & 33 & 21 & 35 & 2.8 & $0.8-9.8$ & & $0.096(0.042)$ & \\
\hline $15-19$ & 6 & 21 & 15 & 22 & $\operatorname{lnf}$ & 3.0-Inf & & $0.11(0.115)$ & \\
\hline $20-39$ & 12 & 29 & 20 & 34 & 2.3 & $0.6-8.9$ & 0.144 & $\operatorname{lnf}(<0.001)$ & 0.090 \\
\hline \multicolumn{10}{|c|}{ 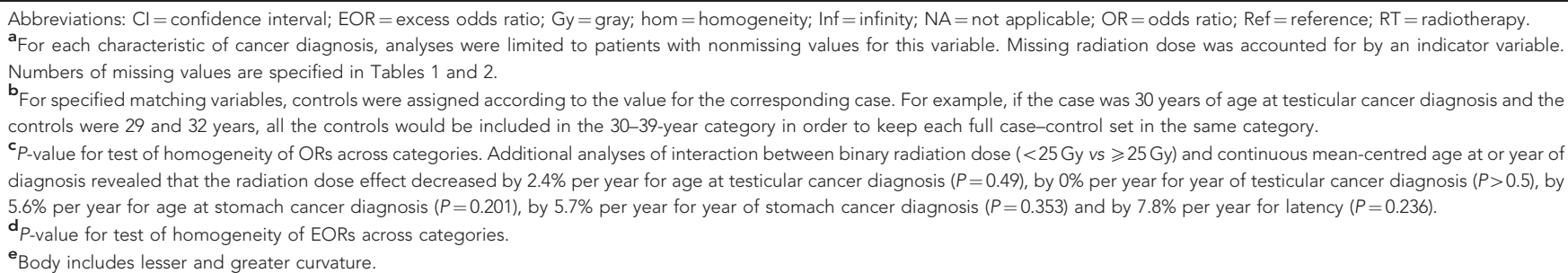 } \\
\hline
\end{tabular}

(95\% CI, 0.12-15.6) and a significant association with procarbazine (Van den Belt-Dusebout et al, 2009) was observed among survivors of either Hodgkin's lymphoma (HL) or TC. However, procarbazine is not used for TC treatment. A larger international nested casecontrol study of stomach cancer after HL (Morton et al, 2013), which also included HL patients from the study of Van den BeltDusebout et al (2009), revealed significant dose-response relationships for radiation (EOR per $\mathrm{Gy}=0.09,95 \%$ CI $0.04-0.21$ ) as well as for alkylating agents $(P$-trend for number of cycles $=0.02)$ with markedly elevated 78 -fold risks for patients who received radiotherapy with stomach doses exceeding $25 \mathrm{~Gy}$ and high-dose procarbazine-containing chemotherapy $(P$-interaction $<0.001)$.

Few studies have evaluated time since radiation exposure and stomach cancer risk. Although elevated risks were observed $\geqslant 15$ years after treatment (Kleinerman et al, 2013; Morton et al, 2013), our study is the first to our knowledge providing evidence of increased radiation-related risks $\geqslant 20$ years after exposure, based on a significantly elevated EOR per Gy for that period. As observed previously (Kleinerman et al, 2013), distal stomach cancers were associated with the highest risks per Gy, and those were closest to the radiation therapy fields and received the highest doses. No other interactions were observed, perhaps because of the small numbers.
Compelling evidence exists that increasing cumulative dose of cisplatin is associated with significantly elevated risks of second leukaemia ( $P$-trend for dose $<0.001$ ) in patients with either TC (Travis et al, 2000) or ovarian cancer (Travis et al, 1999). We observed a nonsignificant 1.4 -fold increased risk of stomach cancer among the 7 cases and 10 controls who received cisplatin, representing the largest evaluation of platinum-related stomach cancer risk to date. Among 6000 non-seminoma patients treated with chemotherapy in the modern era of cisplatin-based chemotherapy (although no information on individual cytotoxic drugs was available), without radiotherapy, a nonsignificant 1.9fold increased stomach cancer risk was observed, based on 3 cases and $<10$ years average follow-up (Fung et al, 2013). The Childhood Cancer Survivor Study, based on 45 cases of second gastrointestinal cancers, found increased risks with abdominal radiation (hazard ratio $=5.4,95 \%$ CI $2.6-11.2$ ) and with platinum agents (hazard ratio $=7.6,95 \%$ CI 2.3-25.5) (Henderson et al, 2012). Results for stomach cancer (6 cases) were not presented separately. In the same study population, a suggestive association between cisplatin exposure and renal carcinoma was observed $(\mathrm{RR}=3.5$, 95\% CI 1.0-11.2) (Wilson et al, 2013). Therefore, further research is warranted to determine whether platinum agents have a role in solid tumour carcinogenesis. 
A major strength of our study is the case-control design nested in an international cohort of 22269 TC patients followed for many decades that enabled us to gather an extensive amount of clinical and demographic information for participating patients and to perform individual dosimetry in order to estimate the radiation dose to the tumour location. Despite the large study base, the size of our study remains relatively small for the evaluation of cisplatin-based chemotherapy (Einhorn and Donohue, 1977). Failure to obtain medical records was more common for patients diagnosed before 1970 and therefore a larger number of cases could not be included from registries that started earlier. However, this is not likely to introduce bias because controls were matched to cases on year of TC diagnosis, registry and birth date. Another challenge is the uncertainty in radiation dose estimation to specific parts of the stomach because of variations in shape, size and location of the stomach. Using a slightly different approach, Van den Belt-Dusebout et al (2009) estimated the average dose to the entire stomach. These differences, together with the small study size, may explain the higher EOR per Gy of 0.84 that they observed compared with 0.27 in this study. Furthermore, we were unable to adjust our analyses for established stomach cancer risk factors such as $H$. pylori infection, family history and smoking (Nomura 1996; International Agency for Research on Cancer, 2004; Forman and Burley, 2006; Brenner et al, 2009), as information was not available for most patients in our study. However, it is unlikely that there is substantial confounding of the treatment-related risks by established risk factors as a strong association between treatment and a risk factor would be required. We are not aware of evidence suggesting that stomach cancer risk factors influence TC treatment or radiation doses.

In this large international study, we observed that patients treated with radiotherapy for TC between 1960 and 1990 are at increased risk of developing stomach cancer, particularly those who received $\geqslant 30 \mathrm{~Gy}$ to the stomach, and that the elevated radiation-associated risk persists for more than two decades. The median age at stomach cancer diagnosis among our cases was relatively young (i.e., 58 years) compared with 69 years in the US general population (Howlader et al, 2013). Although the proportion of TC patients receiving radiotherapy has decreased substantially during recent decades, presently up to one-third of seminoma patients may receive radiotherapy, although with smaller fields and lower doses than those in this study (Jones et al, 2005; Hoffman et al, 2008; Schmoll et al, 2009; Yu et al, 2009; Arvold et al, 2012; National Comprehensive Cancer Network (NCCN), 2013). Our findings add to the knowledge of potential adverse sequelae associated with radiotherapy in TC survivors. When radiation therapy (including a boost to the upper abdomen) is considered in TC treatment plans with curative intent, clinicians and patients should be aware of radiation-related stomach cancer risk that persists for more than 20 years, and carefully consider the short- and long-term risks and benefits of therapy in their decision making.

\section{ACKNOWLEDGEMENTS}

We thank Diane Fuchs, Janet Lawler-Heavner and their staff at Westat, Inc. (Rockville, MD, USA) for administrative assistance in conducting the field studies, and Jeremy Miller (Information Management Services, Silver Spring, MD, USA) for computer programming support. This work was supported by the Intramural Research Program of the National Cancer Institute, National Institutes of Health, Department of Health and Human Services and National Cancer Institute contracts to Cancer Care Ontario, Toronto, Canada (N01-CP-31157); Danish Cancer Society, Copenhagen, Denmark (N01-CP-31019); Finnish Cancer Registry, Helsinki, Finland (N01-CP-31154); Information Management Services, Inc., Silver Spring, USA (N01-CP-31003); Karolinska
Institute, Stockholm, Sweden (N01-CP-31156); University of Iowa, Iowa City, USA (N01-CP-31155); The University of Texas MD Anderson Cancer Center, Houston, USA (N02-CP-55503); and Westat, Inc., Rockville, USA (N02-CP-31136). The Dutch study was also supported by the Lance Armstrong Foundation and the Dutch Cancer Society (Grant No. NKI 04-3068). Dr Travis was supported by National Cancer Institute 1R01 CA 157823-01A1.

\section{CONFLICT OF INTEREST}

The authors declare no conflict of interest.

\section{REFERENCES}

Arvold ND, Catalano PJ, Sweeney CJ, Hoffman KE, Nguyen PL, Balboni TA, Fosså SD, Travis LB, Beard CJ (2012) Barriers to the implementation of surveillance for stage I testicular seminoma. Int J Radiat Oncol Biol Phys 84(2): 383-389.

Berrington de Gonzalez A, Gilbert E, Curtis R, Inskip P, Kleinerman R, Morton L, Rajaraman P, Little MP (2013) Second solid cancers after radiation therapy: A systematic review of the epidemiologic studies of the radiation dose-response relationship. Int J Radiat Oncol Biol Phys 86(2): 224-233.

Biggs ML, Schwartz SM (2007) Cancer of the testis. In: Ries LA, Young JL, Keel GE, Eisner MP, Lin YD, Horner MJ (eds) SEER Survival Monograph: Cancer Survival Among Adults: U.S. SEER Program, 1988-2001, Patient and Tumor Characteristics. National Cancer Institute, SEER Program, NIH Pub. No. 07-6215, Bethesda, MD, pp 175-180.

Birdwell SH, Hancock SL, Varghese A, Cox RS, Hoppe RT (1997) Gastrointestinal cancer after treatment of Hodgkin's disease. Int J Radiat Oncol Biol Phys 37: 67-73.

Brenner H, Rothenbacher D, Arndt V (2009) Epidemiology of stomach cancer. Methods Mol Biol 472: 467-477.

Breslow NE, Day NE (1980) Statistical Methods in Cancer Research: Volume 1 - The Analysis of Case-Control Studies. International Agency for Research on Cancer: Lyon.

Carr JD, Kleinerman RA, Stovall M, Weinstock M, Griem ML, Land CE (2002) Malignant neoplasms after radiation therapy for peptic ulcer. Radiat Res 157: 668-677.

Chia VM, Quraishi SM, Devesa SS, Purdue MP, Cook MB, McGlynn KA (2010) International trends in the incidence of testicular cancer, 1973-2002. Cancer Epidemiol Biomarkers Pre 19(5): 1151-1159.

Dowd SB, Wilson BG (1995) Encyclopedia of Radiographic Positioning. Vol. 2. Saunders: Philadelphia, PA.

Einhorn LH, Donohue J (1977) Cis-diamminedichloroplatinum, vinblastine, and bleomycin combination chemotherapy in disseminated testicular cancer. Ann Intern Med 87(3): 293-298.

Forman D, Burley VJ (2006) Gastric cancer: global pattern of the disease and an overview of environmental risk factors. Best Pract Res Clin Gastroenterol 20(4): 633-649.

Foss Abrahamsen A, Andersen A, Nome O, Jacobsen AB, Holte H, Foss Abrahamsen J, Kvaløy S (2002) Long-term risk of second malignancy after treatment of Hodgkin's disease: the influence of treatment, age and follow-up time. Ann Oncol 13: 1786-1791.

Fung C, Fossa SD, Milano MT, Oldenburg J, Travis LB (2013) Solid tumors after chemotherapy or surgery for testicular nonseminoma: a populationbased study. J Clin Oncol 31(30): 3807-3814.

Garner MJ, Turner MC, Ghadirian P, Krewski D (2005) Epidemiology of testicular cancer: an overview. Int J Cancer 116(3): 331-339.

Gooley TA, Leisenring W, Crowley J, Storer BE (1999) Estimation of failure probabilities in the presence of competing risks: new representations of old estimators. Stat Med 18(6): 695-706.

Henderson TO, Oeffinger KC, Whitton J, Leisenring W, Neglia J, Meadows A, Crotty C, Rubin DT, Diller L, Inskip P, Smith SA, Stovall M, Constine LS, Hammond S, Armstrong GT, Robison LL, Nathan PC (2012) Secondary gastrointestinal cancer in childhood cancer survivors: a cohort study. Ann Intern Med 156(11): 757-766.

Hoffman KE, Chen MH, Punglia RS, Beard CJ, D'Amico AV (2008) Influence of year of diagnosis, patient age, and sociodemographic status on recommending adjuvant radiation treatment for stage I testicular seminoma. J Clin Oncol 26: 3937-3942. 
Horwich A, Fossa S, Huddart R, Dearnaley DP, Stenning S, Aresu M, Bliss JM, Hall E (2014) Second cancer risk and mortality in men treated with radiotherapy for stage I seminoma. Br J Cancer 110: 256-263.

Howlader N, Noone AM, Krapcho M, Garshell J, Miller D, Altekruse SF, Kosary CL, Yu M, Ruhl J, Tatalovich Z, Mariotto A, Lewis DR, Chen HS, Feuer EJ, Cronin KA (eds) (2013) SEER Cancer Statistics Review, 1975-2010. National Cancer Institute: Bethesda, MD. http:// seer.cancer.gov/csr/1975_2010/based on November 2012 SEER data submission, posted to the SEER website, April 2013.

International Agency for Research on Cancer (2004) Tobacco Smoke and Involuntary Smoking. IARC: Lyon.

Jones WG, Fossa SD, Mead GM, Roberts JT, Sokal M, Horwich A, Stenning SP (2005) Randomized trial of 30 versus 20 Gy in the adjuvant treatment of stage I Testicular Seminoma: a report on Medical Research Council Trial TE18, European Organisation for the Research and Treatment of Cancer Trial 30942 (ISRCTN18525328). J Clin Oncol 23(6): 1200-1208.

Kleinerman RA, Smith SA, Holowaty E, Hall P, Pukkala E, Vaalavirta L, Stovall M, Weathers R, Gilbert E, Aleman BM, Kaijser M, Andersson M, Storm H, Joensuu H, Lynch CF, Dores GM, Travis LB, Morton LM, Curtis RE (2013) Radiation dose and subsequent risk for stomach cancer in long-term survivors of cervical cancer. Int J Radiat Oncol Biol Phys 86(5): 922-929.

Kollmannsberger C, Hartmann JT, Kanz L, Bokemeyer C (1999) Therapyrelated malignancies following treatment of germ cell cancer. Int J Cancer 83: 860-863.

Leibel SA, Phillips TL (2004) Textbook of Radiation Oncology. 2nd edn. Saunders: Philadelphia, PA.

Mauch PM, Kalish LA, Marcus KC, Coleman CN, Shulman LN, Krill E, Come S, Silver B, Canellos GP, Tarbell NJ (1996) Second malignancies after treatment for laparotomy staged IA-IIIB Hodgkin's disease: long-term analysis of risk factors and outcome. Blood 87: 3625-3632.

McGlynn KA, Devesa SS, Sigurdson AJ, Brown LM, Tsao L, Tarone RE (2003) Trends in the incidence of testicular germ cell tumors in the United States. Cancer 97(1): 63-70.

Morton LM, Dores GM, Curtis RE, Lynch CF, Stovall M, Hall P, Gilbert ES, Hodgson DC, Storm HH, Johannesen TB, Smith SA, Weathers RE, Andersson M, Fossa SD, Hauptmann M, Holowaty EJ, Joensuu H, Kaijser M, Kleinerman RA, Langmark F, Pukkala E, Vaalavirta L, van den Belt-Dusebout AW, Fraumeni Jr JF, Travis LB, Aleman BM, van Leeuwen FE (2013) Stomach cancer risk after treatment for Hodgkin lymphoma. J Clin Oncol 31(27): 3369-3377.

National Comprehensive Cancer Network (NCCN) (2013) Clinical Practice Guidelines in Oncology. Testicular Cancer. Version 1.2013, www.NCCN.org.

National Council on Radiation Protection and Measurements Scientific Committee 1-17 (2011) Second Primary Cancers and Cardiovascular Disease After Radiotherapy. NCRP Report No. 170. National Council on Radiation Protection and Measurements: Bethesda, MD.

Nomura A (1996) Stomach cancer. In Cancer Epidemiology and Prevention, Schottenfeld D, Fraumeni JF (eds) 2nd edn Chapter 34. pp 707-724. Oxford University Press: New York.

Preston DL, Lubin JH, Pierce DA, McConney MA (1993) Epicure: User's Guide. HiroSoft International Corporation: Seattle, WA.

Preston DL, Ron E, Tokuoka S, Funamoto S, Nishi N, Soda M, Mabuchi K, Kodama K (2007) Solid cancer incidence in atomic bomb survivors: 1958-1998. Radiat Res 168: 1-64.

Robinson D, Moller H, Horwich A (2007) Mortality and incidence of second cancers following treatment for testicular cancer. Br J Cancer 96: 529-533.

Schmoll HJ, Jordan K, Huddart R, Laguna MP, Horwich A, Fizazi K, Kataja V. ESMO Guidelines Working Group (2009) Testicular seminoma: ESMO clinical recommendations for diagnosis, treatment and follow-up. Ann Oncol 20(Suppl 4): 83-88.

Stovall M, Weathers R, Kasper C, Smith SA, Travis L, Ron E, Kleinerman R (2006) Dose reconstruction for therapeutic and diagnostic radiation exposures: use in epidemiological studies. Radiat Res 166: 141-157.
Swerdlow AJ, Barber JA, Hudson GV, Cunningham D, Gupta RK, Hancock BW, Horwich A, Lister TA, Linch DC (2000) Risk of second malignancy after Hodgkin's disease in a collaborative British cohort: The relation to age at treatment. J Clin Oncol 18: 498-509.

Travis LB, Curtis RE, Storm H, Hall P, Holowaty E, Van Leeuwen FE, Kohler BA, Pukkala E, Lynch CF, Andersson M, Bergfeldt K, Clarke EA, Wiklund T, Stoter G, Gospodarowicz M, Sturgeon J, Fraumeni Jr JF, Boice Jr JD (1997) Risk of second malignant neoplasms among long-term survivors of testicular cancer. J Natl Cancer Inst 89: 1429-1439.

Travis LB, Holowaty EJ, Bergfeldt K, Lynch CF, Kohler BA, Wiklund T, Curtis RE, Hall P, Andersson M, Pukkala E, Sturgeon J, Stovall M (1999) Risk of leukemia after platinum-based chemotherapy for ovarian cancer. N Engl J Med 340(5): 351-357.

Travis LB, Andersson M, Gospodarowicz M, Van Leeuwen FE, Bergfeldt K, Lynch CF, Curtis RE, Kohler BA, Wiklund T, Storm H, Holowaty E, Hall P, Pukkala E, Sleijfer DT, Clarke EA, Boice Jr JD, Stovall M, Gilbert E (2000) Treatment-associated leukemia following testicular cancer. J Natl Cancer Inst 92(14): 1165-1171.

Travis LB, Fossa SD, Schonfeld SJ, McMaster ML, Lynch CF, Storm H, Hall P, Holowaty E, Andersen A, Pukkala E, Andersson M, Kaijser M, Gospodarowicz M, Joensuu T, Cohen RJ, Boice Jr JD, Dores GM, Gilbert ES (2005) Second cancers among 40,576 testicular cancer patients: focus on long-term survivors. J Natl Cancer Inst 97(18): 1354-1365.

Travis LB, Ng AK, Allan JM, Pui CH, Kennedy AR, Xu XG, Purdy JA, Applegate K, Yahalom J, Constine LS, Gilbert ES, Boice Jr JD (2012) Second malignant neoplasms and cardiovascular disease following radiotherapy. J Natl Cancer Inst 104(5): 357-370.

Van den Belt-Dusebout AW, De Wit R, Gietema JA, Horenblas S, Louwman MW, Ribot JG, Hoekstra HJ, Ouwens GM, Aleman BM, Van Leeuwen FE (2007) Treatment-specific risks of second malignancies and cardiovascular disease in 5-year survivors of testicular cancer. J Clin Oncol 25(28): 4370-4378.

Van den Belt-Dusebout AW, Aleman BM, Besseling G, de Bruin ML, Hauptmann M, Van 't Veer MB, De Wit R, Ribot JG, Noordijk EM, Kerst JM, Gietema JA, Van Leeuwen FE (2009) Roles of radiation dose and chemotherapy in the etiology of stomach cancer as a second malignancy. Int J Radiat Oncol Biol Phys 75: 1420-1429.

Van Leeuwen FE, Stiggelbout AM, Van den Belt-Dusebout AW, Noyon R, Eliel MR, Van Kerkhoff EH, Delemarre JF, Somers R (1993) Second cancer risk following testicular cancer: a follow-up study of 1,909 patients. J Clin Oncol 11: 415-424.

Van Leeuwen FE, Klokman WJ, Van 't Veer MB, Hagenbeek A, Krol AD, Vetter UA, Schaapveld M, Van Heerde P, Burgers JM, Somers R, Aleman BM (2000) Long-term risk of second malignancy in survivors of Hodgkin's disease treated during adolescence or young adulthood. J Clin Oncol 18: 487-497.

Verdecchia A, Francisci S, Brenner H, Gatta G, Micheli A, Mangone L, Kunkler I. EUROCARE-4 Working Group (2007) Recent cancer survival in Europe: a 2000-02 period analysis of EUROCARE-4 data. Lancet Oncol 8(9): 784-796.

Weiss HA, Darby SC, Doll R (1994) Cancer mortality following X-ray treatment for ankylosing spondylitis. Int J Cancer 59(3): 327-338.

Wilson CL, Ness KK, Neglia JP, Hammond S, Shnorhavorian M, Leisenring WL, Stovall M, Robison LL, Armstrong GT (2013) Renal carcinoma after childhood cancer: a report from the childhood cancer survivor study. J Natl Cancer Inst 105(7): 504-508.

Yu HY, Madison RA, Setodji CM, Saigal CS (2009) Quality of surveillance for stage I testis cancer in the community. J Clin Oncol 27: 4327-4332.

This work is published under the standard license to publish agreement. After 12 months the work will become freely available and the license terms will switch to a Creative Commons AttributionNonCommercial-Share Alike 3.0 Unported License.

Supplementary Information accompanies this paper on British Journal of Cancer website (http://www.nature.com/bjc) 